\title{
Investment Decision Support Based on Interval Type-2 Fuzzy Expert System
}

\author{
${\text { Zuzana Jankova }{ }^{1, *} \text {, Dipak Kumar Jana }}^{2}$, Petr Dostal ${ }^{1}$ \\ ${ }^{1}$ Brno University of Technology, Faculty of Business and Management, Institute of Informatics \\ Kolejni 2906/4, Kralovo Pole, 61200 Brno, Czech Republic \\ E-mail.zuzana.jankova@vutbr.cz; dostal@fbm.vutbr.cz. \\ * Corresponding author
}

${ }^{2}$ Haldia Institute of Technology, School of Applied Science \& Humanities

Haldia, Purba Midnapur-721657, West Bengal, India

E-mail.dipakjana@gmail.com

cross $^{\text {ref }}$ http://dx.doi.org/10.5755/j01.ee.32.2.24884

The decision-making process on investing in financial markets is a very complex and difficult task, mainly due to the chaotic behavior and high uncertainty in the development of the prices of investment instruments. For this reason, financial markets are increasingly using means of artificial intelligence, namely fuzzy logic, which is able to capture the nonlinear behavior.Fuzzy logic provides a way to draw definitive conclusions from vague, ambiguous, or inaccurate information.However, there are some drawbacks associated with type-1 fuzzy logic, so the type-2 fuzzy logic comes forward, which can work with greater uncertainty. Type-2 fuzzy logic works with a new third dimension fuzzy set that provides additional degrees of freedom and allows to model and process numerical and linguistic uncertainties directly. The paper applies type-2 fuzzy logic to the stock market with the aim to create a simple and understandable model for deciding on investing in investment instruments, which is important for investors in this area. The proposed type-2 fuzzy model uses return, risk, dividend and total expense ratio of ETF as input variables. The created system is able to generate aggregated models from a certain number of language rules, which allows the investor to understand the created financial model. Using type-2 fuzzy logic can lead to more realistic and accurate results than type-1 fuzzy logic.

Keywords: Fuzzy Logic; Interval Type-2 Fuzzy Logic; Investment Analysis; Soft Computing; T2FLS.

\section{Introduction}

Currently, linear models are widely used for forecasting, but these models are greatly limited, especially when applied to seasonal and nonlinear uncertainty issues. Hence, nonlinear methods such as neural networks, fuzzy logic, and genetic algorithms attract more and more attention. Fuzzy Logic provides a way to draw definitive conclusions from vague, ambiguous, or inaccurate information. An artificial neural network is widely accepted mainly because of its ability to learn and reveal relationships between non-linear variables. Many researchers agree that artificial intelligence surpasses traditional models based on statistical regressions, as reported by Tung \& Le (2017). In particular, fuzzy logic is able to work with inaccurate data and information in a relatively simple way as well as to understand the meaning of words in natural language. Surprisingly, fuzzy logic, unlike other techniques, is able to use such vaguely defined expertise to its advantage. Zadeh (1965) called this fact the principle of incompatibility, because fuzzy logic is able to capture the relationship between the relevance and accuracy of information. Zadeh (1965) adds that in a number of situations a person decides on the basis of inaccurate or indeterminate information that is gathered from outside, yet the result of the activity obtained from these vague data is still sufficient. The potential of fuzzy logic to improve forecasting models can be found in various applications (such as Jana \& Ghosh,
2018) due to its known ability to bridge the gap between numerical data (quantitative information) and language expression (qualitative information),

In particular, financial markets are influenced by deterministic and random factors. Furthermore, Dostal \& Lin (2018) add that the time series of stock titles, commodities, currency rates, etc. are influenced by complex economic and psychological phenomena that contain a high proportion of chaos, hence fuzzy logic and other soft computing tools the best that currently exist for processing and evaluating economic and financial information and data. Similarly, Rajab \& Sharm (2019) report that stock price prediction is a complex and difficult task due to chaotic behavior and high uncertainty in the development of equity market prices. The design of a highly accurate, simple and understandable predictive model is of paramount importance in this area. Yu \& Yan (2019) add that since financial data contains complex, incomplete and fuzzy information, anticipating their developmental trends is an extremely difficult challenge. Fluctuations in financial data depend on innumerable correlated, constantly changing factors. Therefore, predicting and analyzing financial data is a non-linear and time-dependent problem. Chang et al. (2011) conclude and state that stock market forecasts can only be successful with the use of tools and techniques that can overcome the problem of price uncertainty and nonlinearity. Wang \&Wang (2015) report that fuzzy logic and neural networks are increasingly being used in financial 
markets, and their art of prediction is widely acknowledged in particular because of the ability to capture non-linear behavior. The same results are provided by Jankova (2019). Rao et al. (2017) argue that investment decisions based on a fuzzy model can be particularly useful for investors looking to minimize risk in solving their long-term investment portfolio. The authors recommend fuzzy logic as a suitable method to solve the complexity of stock market. Othman \& Schneider (2010) consider fuzzy logic to be easier and more beneficial for investors.

However, as Melin \& Castillo (2014) and Castillo et al. (2007) stated, it is not reasonable to use the exact functions of fuzzy logic belonging to something uncertain. As further described by Tang et al. (2020) type-1 fuzzy logic may be unsuitable for solving cases in the real world due to the growing uncertainty of the problem. In this case, it is necessary to use another type of fuzzy logic that can handle these uncertainties, namely the type-2 fuzzy logic (T2FLS) system. Castillo et al. (2013) report that T2FLS are essentially "fuzzy fuzzy" sets that generalize type-1 fuzzy sets and systems to work with greater uncertainty. Alhassan \& Hagras (2018) report that type-2 fuzzy set is reduced to a type-1 fuzzy set if there is no uncertainty that is analogous to the probability of decreasing to determinism when unpredictability disappears. The membership function of the general type-2 fuzzy set is three-dimensional and includes the footprint of uncertainty (FOU). It is a new third dimension of the fuzzy set that provides additional degrees of freedom and allows you to directly model and process numerical and linguistic uncertainties. Chen et al. (2018) note that T2FLS have a higher approximation capability than neural networks. However, researchers had to wait for some time to develop the theory. Progress T2FLS primarily limited hardware equipment.Similarly, Wang et al. (2018) and Liu et al. (2019) note that type 2 fuzzy sets attract much more interest from scientists because they are able to handle uncertain and inaccurate information better than type-1 fuzzy sets.

The decision-making processes are very complicated in the economy and finance because they include political, social, psychological, economic, financial, and other factors.There are thousands of theories and methodologies with various success of application in real world. The theory and application of fuzzy processing are very promising, especially newly discovered type- 2 fuzzy method, which is able to include additional higher level of uncertainty resulting from unclear, uncertain or inaccurate data and, thus enables better description of the economy and financial phenomena in their solution of real world problems. We are searching for a new approach to the type-2 fuzzy model to support decision-making, which allows investors to increase the quality and speed of the decision-making processes in real world. The motivation for this research is the fact that the issue of investment funds on the stock market has not yet been sufficiently explored and tested. We believe that this issue is especially important for investors, as a suitable and accurate model can serve as a support for deciding in which investment fund to invest.

The aim of the paper is to apply a higher degree of fuzzy logic, specifically type-2 fuzzy logic as a supporting tool for investment decision making. T2FLS is used to make decisions about investing in exchange-traded funds on the
US stock market, the largest ETFs organizers in the world. The stock market is characterized by chaotic behaviour as described above, so it is preferable to use type-2 fuzzy logic rather than type-1 fuzzy logic because T2FLS is able to cover the higher degree of uncertainty arising from the typical features of financial markets. T2FLS is designed to increase the clarity of the generated model and achieve better performance.

\section{Literature Review}

Jilani\& Burney (2008) presented a simple prognostic method of fuzzy time series. Dourra et al. (2002) used fuzzy information technology in their work through technical analysis and simulate human behavior in stock trading. Escobar et al. (2013) proposed an indicator for technical analysis based on fuzzy logic, which includes the subjective features of the investor. The authors highlight the approach of fuzzy logic because of the ability to represent a "human" way of decision making that a non-investor in the real market has. Wang (2018) proposed a data frame to predict stock price prices using fuzzy time series. His method uses two key technologies, the theory of fuzzy sets and the classical method of forecasting time series. Experimental results suggested that the proposed predictive framework provides better performance. Naranjo et al. (2018) proposed a methodology for detecting candlestick patterns in a stock trading system using fuzzy logic. Candlestick based rules are more natural and realistic than standard crisp rules. The performance of the smart stock trading system is tested in two different stock market portfolios. The created model is more stable and profitable than other trading systems. Rustam et al. (2018) appliedsupport vector machines and fuzzy kernel c-means to predict the price movement of Indonesian stock market stock prices by focusing on the banking subsector. Based on historical stock data, eight technical indicators for model entry were calculated. In a particular case, the best model is the entire FKCM observation. Camara et al. (2018) used a computing intelligent tool that uses fuzzy logic data analysis to predict the effects of hurricanes on the stock market. Liu \& Zhang (2019) used fuzzy time series to analyze and forecast stock prices of State Bank of India and Dow-Jones Industrial Average (DJIA). The authors' experimental results show that the proposed model overcomes other time series models and can handle large amounts of data. Chen et al. (2019) dealt with the pricing of a European call option and studying Greek letters of options in a fuzzy environment. The authors deal with the development of a fuzzy pattern of European call option provided that the stock return is a Gaussian fuzzy number. The results show that fuzzy options are closer to theoretical options derived from the Black-Scholes model. Gautam \&Abhishekh (2019) developed a new moving average based prognostic approach on the fuzzy time series data set. The developed moving average method of fuzzy time series provides improved prognostic output with the smallest RMSE, which shows that the new method is much better than other existing models available in the literature.

Recently, type- 2 fuzzy logic has gained popularity in a wide range of applications, mainly due to its ability to handle a higher degree of uncertainty. Linag \& Mendel (2000) point out that the knowledge that is used to construct 
rules in type-1 fuzzy logic (T1FLS) is uncertain. There are three ways in which such a rule's uncertainty can appear: (1) words that are used in antecedents and consequences of rules can mean different things to different people; (2) consequences of voting in a panel of experts often differ for the same rules; (3) noise in training data. Uncertainty of antecedents or consequents is transformed into an antecedent and consequent membership function. Type-1 fuzzy logic systems are unable to directly incorporate these uncertainties, while type-2 fuzzy logic systems can handle this uncertainty. Furthermore, according to Zarandi et al. (2009) it should be noted that type-2 fuzzy sets can model and minimize the effect of uncertainty in rules-based fuzzy systems. The effects of uncertainty can be minimized by optimizing the type- 2 fuzzy set parameters during the training process. Type-2 fuzzy logic is particularly useful when it is difficult to determine the exact functions of fuzzy set.

Due to the higher degree of uncertainty, T2FLS is applied to financial market issues. These studies include Jianga et al. (2018), who designed interval T2FLS to predict stock index in Taiwan, DJIA and NASDAQ using fuzzy time series. The results of fuzzy logic are compared with non-parametric statistical testing, stating that their proposed model exceeds other methods. Zarandi et al. (2009) applied a type-2 fuzzy model to analyze the prices of automotive equity instruments in Asia using technical and fundamental indicators. Their results are very encouraging and can be implemented to forecast instrument prices in trading systems. Huarng \& Yu (2005) have designed a type-2 fuzzy model to predict the TAIEX index that achieves better results than the type-1 fuzzy model. Liuet et al. (2012) introduced a type-2 neuro fuzzy model for TAIEX prediction. Their results showed that this method showed higher prediction accuracy without the use of additional information. Hasuike \&Ishii (2009) discussed the problem of choosing a type-2 fuzzy portfolio with expected returns with respect to investor's subjectivity. Bernardo et al. (2012) designed T2FLS, which is able to generate aggregate models from a predetermined number of language rules, allowing the user to understand the generated models for predicting stock market opportunities. Jankova \& Dostal
(2019) applied type-2 fuzzy logic to the Czech stock market and create a model that is used to decide on investing in PX index stocks. Runkler et al. (2017) presented a new approach to using type-2 fuzzy sets in decision-making with regard to the risk associated with this decision. Considering the level of risk increases the scope for decision-making to allow better decision making. Vella \& Lon Ng (2016) investigated the ability of higher order fuzzy systems to cope with increased uncertainty, which is mostly due to market microstructure noise. The authors proposed an innovative approach to design the type-2 interval model, which is based on a generalized type-1 ANFIS approach. The proposed model achieves significant performance improvements over standard ANFIS and Buy and Hold methods. Zhang et al. (2017) used T2FLS to validate better taxation performance methodology at the Shanghai Stock Exchange Composite Index and Taiwan Stock Capital Capitalized Weighted Index. The experimental results show that the proposed method overcomes other basic methods. Pulido \& Melin (2016) represented the optimization of fuzzy type-1 and type-2 file neural networks for predicting complex time series on the Taiwanese Stock Exchange (TAIPEX).

\section{Methodology}

The T2FLS structure is very similar to the T1FLS structure. Figure 1 shows the structure of T2FLS. The measured real variables are first transformed in a fuzzification block into linguistic variables, with the linguistic variables based on the basic linguistic variables. Dostal (2011) states that three to seven attributes of this basic variable are usually used. The degree of attribute of a given variable in a set is represented by a mathematical function. Three types of fuzzification are available in T2FLS. If the measured data is perfect, modeled as a sharp set, data with noise and data with stationary noise are modeled as type-1 fuzzy sets, with non-stationary noise modeled as type- 2 fuzzy sets. The latter type of fuzzification cannot be performed in T1FLS.

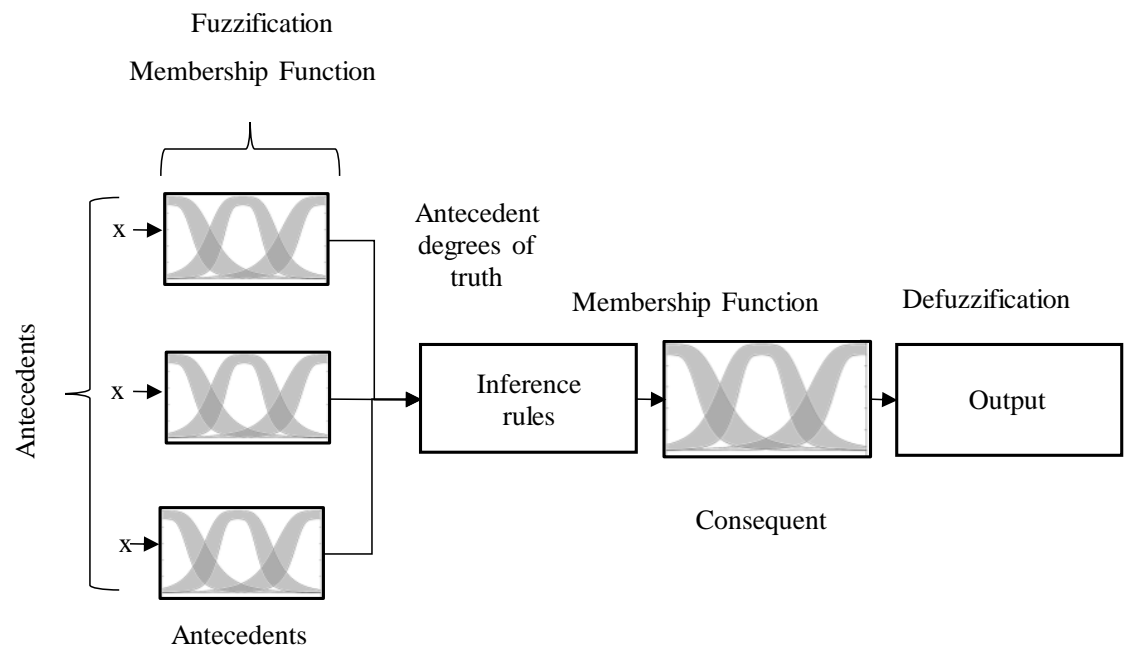

Figure 1. Structure of Type-2 Fuzzy Logic System 
As reported by Medasani et al. (1998), all existing T2FLS membership functions are modified versions of conventional T1FLS membership functions. In other words, the basis of the membership functions of the original type-1 is blurred if the practitioner is uncertain about the value of the membership function of a particular point. There are a number of type-2 fuzzy membership functions, such as triangular, Gaussian, trapezoidal, sigmoidal, etc.as noted by Wang et al. (2018). Gaussian membership function is widely used in literature in which uncertainty is associated with mean and standard deviation.

Kayacan et al. (2018) adds that in applications of the theory of fuzzy sets, the membership functions are chosen based on the subjective perception of vague or inaccurate categories. Furthermore, there are no criteria to assess the appropriateness or correctness of the chosen membership function. Type-2 fuzzy set is denoted $\tilde{A}$ is charakterized type-2 membership function $\mu_{\tilde{A}}(x, u)$, where $x \in X, \forall u \in$ $J_{x}^{u} \subseteq[0,1]$ and $0 \leq \mu_{\tilde{A}}(x, u) \leq 1$ is mathematically defined (Jana \&Ghosh, 2018):

$$
\begin{aligned}
\tilde{A} & =\left\{\left(x, \mu_{\tilde{A}}(x)\right) \mid x \in X\right\} \\
\tilde{A} & =\left\{\left(x, u, \mu_{\tilde{A}}(x, u)\right) \mid x \in X, \forall u\right. \\
\in & \left.J_{x}^{u}[0,1]\right\}
\end{aligned}
$$

If type-2 fuzzy set $\tilde{A}$ is a continuous variable, the expression has the form:

$$
\tilde{A}=\left\{\int_{x \in X}\left[\int_{u \in J_{x}^{u}} f_{x}(u) / u\right] / x\right\}
$$

where $\iint$ denotes a connection between $x$ and $u$. If type2 fuzzy set $\tilde{A}$ is discrete, then the expression has the form:

$$
\begin{aligned}
& \tilde{A}=\left\{\sum_{x \in X} \mu_{\tilde{A}}(x) / x\right\} \\
& \tilde{A}=\left\{\sum_{i=1}^{n}\left[\sum_{j=1}^{m_{i}} f_{x_{i}}\left(u_{j}\right) / u_{i j}\right] / x_{i}\right\}
\end{aligned}
$$

where $\sum \sum$ denotes the connection between $x$ and $u$. Assuming $f_{x}(x)=1, \forall u \in\left[J_{-x}^{u}, J_{x}^{-u}\right] \subseteq[0,1]$, is type-2 membership function $\mu_{\tilde{A}}(x, u)$ expressed by type-1 inferior membership function $J_{-x}^{u}=\mu_{A}(x)$ and type-1 superior, $J_{x}^{-u}=\mu_{A}(x)$ s then called the type-2 interval fuzzy set denoted by the following mathematical formula:

$$
\begin{gathered}
\tilde{A}=\{(x, u, 1) \mid \forall x \in X, \forall u \\
\in\left[\mu_{-A}(x), \bar{\mu}_{A}(x)\right] \\
\subseteq[0,1]\} \\
\tilde{A}=\left\{\int_{x \in X}\left[\int_{u \in\left[J_{-x}^{u}, J_{x}^{-u}\right] \subseteq[0,1]} 1 / u\right] / x\right\} \\
\tilde{A}=\left\{\int_{x \in X}\left[\int_{u \in\left[\mu_{-A}(x), \bar{\mu}_{A}(x)\right] \subseteq[0,1]} 1 / u\right] / x\right\}
\end{gathered}
$$

The uncertainty is then determined by combining all the membership that are labeled as footprint of uncertainty (FOU). The size of the FOU depends directly on the uncertainty that the type- 2 fuzzy set mediates. FOU is as follows:

$$
\begin{aligned}
\operatorname{FOU}(\tilde{A})=\bigcup_{\forall x \in A} J_{x} & \\
& =\left\{(x, u): u \in J_{x}\right. \\
& \subseteq[0,1]\}
\end{aligned}
$$

The upper and lower membership functions of the type2 fuzzy $\tilde{A}$ are two type- 1 membership functions.

$$
J_{x}=\left[\mu_{\underline{x}}(x), \mu_{\bar{x}}(x)\right]
$$

Using the FOU, a given formula can also be expressed as:

$$
\operatorname{FOU}(\tilde{X})=\bigcup_{x \in \tilde{A}}\left[\mu_{\underline{x}}(x), \mu_{\bar{x}}(x)\right]
$$

The fuzzification is followed by a fuzzy inference that defines the behavior of the system using the IF-THEN rules and the language level evaluating the status of membership or veracity of the variable. Each combination of the attributes of the variables entering the system and occurring in the condition expresses one rule.Consequently, for each rule, the degree of support or the weight of the rule in the system needs to be determined. The result of fuzzy inference, as mentioned by Dostal et al. (2005) is a language variable. In most applications, however, a final output is required as a specific number, and not a fuzzy set. As a result, the output fuzzy set must be converted to a number.

Fuzzy rules define the connection between input and output fuzzy variables. T2FLS rules can offer an alternative if there is a need to model the uncertainty of the problem. T2FLS rules are better at not using the exact levels of membership, for example, when training data is affected by noise. Fuzzy rule has, according to Castillo et al. (2007), the following form, where the antecedent and the consequent are now type 2 :

$$
R^{n}: \text { IF } x_{1} \text { is } X_{1}^{n} \text { and .... and } x_{l} \text { is } X_{l}^{n} \text { THEN } y \text { is }
$$

where $X_{l}^{n}$ is the T2FLS antecedent and $Y^{n}=\left[\underline{y}^{n}, \bar{y}^{n}\right]$ is the T2FLS consequent. Here $\underline{y}^{n}$ and $\bar{y}^{n}$, as stated by Taskin \& Kumbasar (2015), there may be consequences or linear functions:

$$
\begin{aligned}
& \underline{y}^{n}=\underline{a}_{1}^{n} x_{1}+\cdots+\underline{a}_{l}^{n} x_{l}+\underline{b}^{n} \\
& \bar{y}^{n}=\bar{a}_{1}^{n} x_{1}+\cdots+\bar{a}_{l}^{n} x_{l}+\bar{b}^{n}
\end{aligned}
$$

wherein the antecedent is a compound fuzzy logical expression of one or more simple fuzzy expressions associated with fuzzy operators, and the consequent is an expression that assigns fuzzy values to an output variable. The inference system evaluates all rules and combines the weights of the consequence of all relevant rules into one fuzzy set using a summary operation. 
In T1FLS, the conversion process to a specific number is called defuzzification. There are many ways to achieve the result, for example, to calculate the center of gravity of the membership function for a fuzzy set, calculate the weighted average of the center of gravity of each membership function, etc. However, the matter is much more complicated for T2FLS because moving from type-2 fuzzy to a crisp set requires two steps. The first step is named as a type reducer in which the type- 2 fuzzy set is reduced to the type- 1 fuzzy set. There are as many type reducers as the T1FLS defuzzification methods. The most commonly used algorithm developed by Karnik \& Mendel (2001) and Mendel (2001) is iterative and fast. The type reducer generates a fuzzy set T1FLS, which is then transformed into an output by defuzzification. In the case of using the center-of-sum method (cos) of the type reducer, its mathematical expression, according to Taskin \& Kumbasar (2015), is as follows:

$$
Y_{c o s}(x)=\left[y_{t}, y_{r}\right]=\bigcup_{f^{n} \in F^{n}(x)} \frac{\sum_{n=1}^{N} y^{n} f^{n}}{\sum_{n=1}^{N} f^{n}}
$$

where $y_{t}$ and $y_{r}$ defined as:

$$
\begin{gathered}
y_{t}=\frac{\sum_{n=1}^{L} \underline{y^{n} f^{-n}+\sum_{n=L+1}^{N} \underline{y^{n} f^{n}}}}{\sum_{n=1}^{L} f^{-n}+\sum_{n=L+1}^{N} f^{n}} \\
y_{r}=\frac{\sum_{n=1}^{R} \underline{f}^{n} y^{-n}+\sum_{n=R+1}^{N} y^{-n} f^{-n}}{\sum_{n=1}^{R} \underline{f}^{n}+\sum_{n=R+1}^{N} f^{-n}}
\end{gathered}
$$

wherein $\mathrm{R}$ and $\mathrm{L}$ are points that can be found using the iterative KM algorithm.

The second step of processing the output that follows the type reducer is still called defuzzification. In Figure 1 it can be seen that there may be two numerical outputs for T2FLS designated as crisp outputs and a type reduced set. The latter expresses the degree of uncertainty that T2FLS has due to uncertain input measurements (Mendel, 2007; Zarandi et al., 2009). Average values are obtained from the type reducer, and the calculation of the defuzzification output is as follows:

$$
y=\frac{y_{t}+y_{r}}{2}
$$

\section{Experimental Results and Analysis}

This paper uses T2FLS to make decision making process on investing in exchange traded funds. For the time being, the application of higher degree of fuzzy logic has been underused for the stock market forecast, as recorded by the literature review. The following part of the paper presents not only selected data sample but also the required outputs. Then a model is created based on the T2FLS. The model output is a signal to buy or sell the Exchange Traded Funds (ETF) stock.

\section{Data Sample}

For the T2FLS model creation, 10 ETFs in the real estate sector are selected. The most important characteristic feature of the ETF, as the name suggests, is that it is traded similarly to stock exchange. They are valued and traded continuously during the trading day, allowing investors to buy or sell without delay. Stock exchange funds invest in a defined index or the basket of assets, the investors are allowed to invest in the entire portfolio with a single share. These are open-ended, passive-funded funds that aim to copy the benchmark as accurately as possible. ETFs have become very popular over the past decade, mainly due to their very low cost, high liquidity and lower risk due to good portfolio diversification.

ETFs are a relatively new investment instrument that provides certain advantages over traditional mutual funds. Above all, ETFs are very low-cost funds, their goal is the most faithful replication of the underlying index, which is referred to as a benchmark. The largest and most liquid stock market, the US stock market, is selected for this study, which, according to the ICI Factbook (2018), offers 1,832 ETFs and \$ 3.4 trillion of assets under management. Table 1 shows summary statistics of input variables of selected ETFs entering the model.

\section{Financial Indicators}

The key factors for investment decisions that investors take into account are usually the return and risk of the investment, as confirmed by Fang et al. (2006). Some are also inclined to include the dividend resulting from the investment according to Gupt et al. (2008). Other authors prefer investment liquidity (Arenas et al., 2001). Li et al. (2000) or Khayamim et al. (2018) argues that ignoring the cost of an investment leads to inaccurate and inefficient models that can lead to a loss-making investment. Based on the above, the following are selected as input variables for the presented model: return, dividend, risk and total expense ratio (TER). The output of the model is the decision whether to invest in the ETF or not.

Table 1

Summary Statistic for Inputs Variables

\begin{tabular}{clcccccc}
\hline & Statistics & Mean & Max & Min & Sd & Skewness & Kurtois \\
\hline \multirow{4}{*}{ Inputs } & Risk & 0,037 & 0,055 & 0,015 & 0,009 & $-0,826$ & 0,061 \\
& Return & 0,010 & 0,032 & $-0,006$ & 0,009 & 0,910 & 0,118 \\
& Dividend & 0,039 & 0,049 & 0,029 & 0,007 & 0,260 & $-1,426$ \\
& TER & 0,004 & 0,006 & 0,001 & 0,002 & $-0,660$ & $-0,976$ \\
\hline
\end{tabular}


Table 1 summarizes the basic statistics of input variables. On average, the risk of selected ETFs was around $3.7 \%$ and return was around $1.0 \%$. The amount of dividends paid and the TER indicator are almost identical for the monitored funds. The table above shows the fact that ETFs are very low-cost funds with an average cost of $0.4 \%$, which is a significant difference compared to conventional mutual funds. ETFs are also suitable for investors seeking stable dividend income, as the ETF's minimum dividend is $2.9 \%$.

\section{Experimental Results}

Fuzzy logic is able to accept an explanation of ambiguous and vague thinking. Fuzzy Logic is a very popular tool for solving various problems. The two most common types of fuzzy inference system are Mamdani and Sugeno. The following study uses T2FLS type Sugeno. Sugeno T2FLS model design consists of a total of four input variables divided into a total of three attributes and one output variable. The structure of the model is shown in Figure 2.

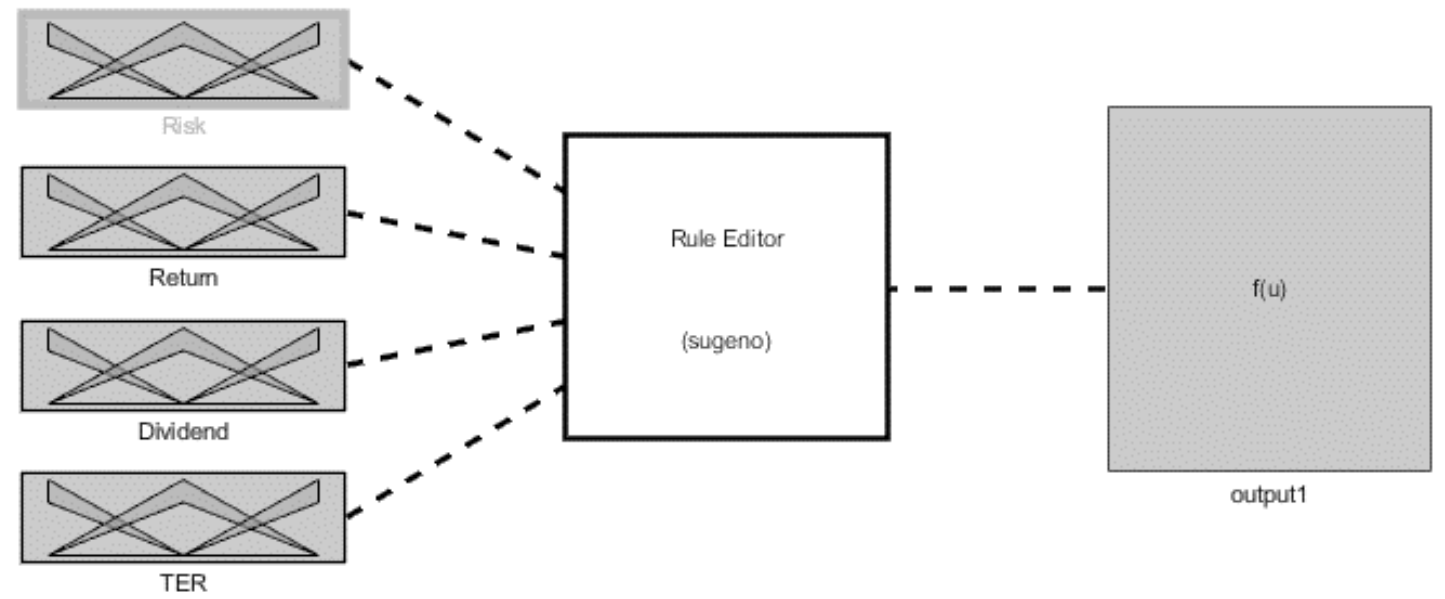

Figure 2.Structure of the Sugeno T2FLS Model

Although the choice of membership function is subjective and depends on the choice of the expert and the sample of the data set, several studies are carried out focusing on comparing the different types of these functions in order to find the most appropriate one. Mayilvaganan \& Naidu (2011) found that the best performance and results were achieved by the Gaussian membership function. Bell and trapezoidal membership function worse than Gaussian. The above study is followed by Talpur et al. (2017), who focused on comparing Gaussian, triangular, trapezoidal, and bell membership functions. Their study shows that the Gaussian membership function is most appropriate in the ANFIS model. In their research, Esfahanipour \&Aghamiri (2010) used the Gaussian membership function in the ANFIS model to test data on investment instruments. For this reason, in the proposed T2FLS model, the Gaussian membership function is chosen. Three attributes (LOW, MEDIUM, HIGH) of the membership function are used, which are further divided into UPPER and LOWER function in order to capture a higher degree of uncertainty.

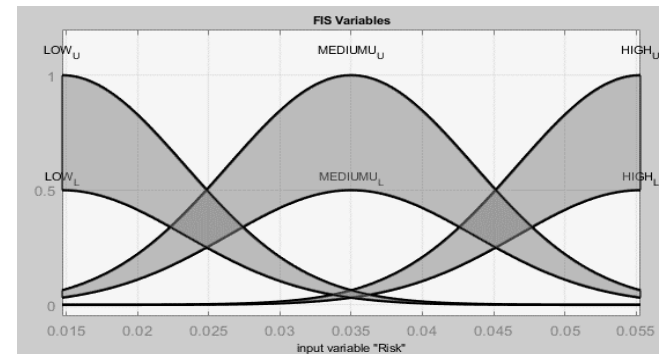

Figure 3. Risk T2F Membership Function
The risk can be characterized as the possibility that the expected return deviates from the actual return. This is a certain degree of uncertainty associated with the expected return. The Gaussian T2F membership function for risk is shown in Figure 3. Return can be understood as an investor's remuneration for the risk incurred. The goal of investors is to achieve the highest possible return while minimizing risk. The Gaussian T2F membership function for return is shown in Figure 4. ETFs paying dividends generate regular income for investors. All ETFs selected pay dividends on a quarterly basis. Investors can benefit not only from potentially rising ETF share prices but also from dividend income. The type-2 fuzzy membership function for dividend is shown in Figure 5. TER is a measure of the total cost of managing and operating the fund. These costs include management fees and additional expenses, such as trading fees, legal fees, auditor fees, and other operational expenses. The total cost of the fund is divided by the total assets of the fund to reach the percentage that represents the TER. For ETFs, TERs are at a very low level compared to conventional mutual funds. The type-2 fuzzy membership function for TER is shown in Figure 6.

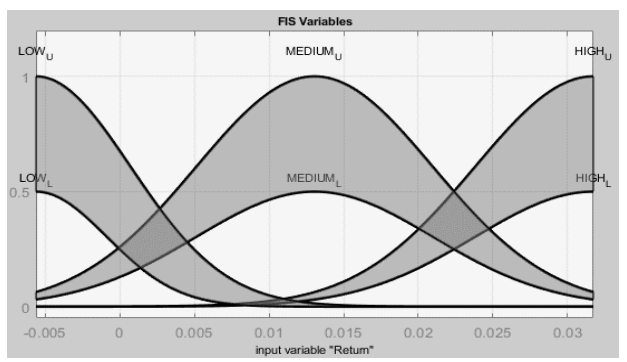

Figure 4. Return T2F Membership Function 


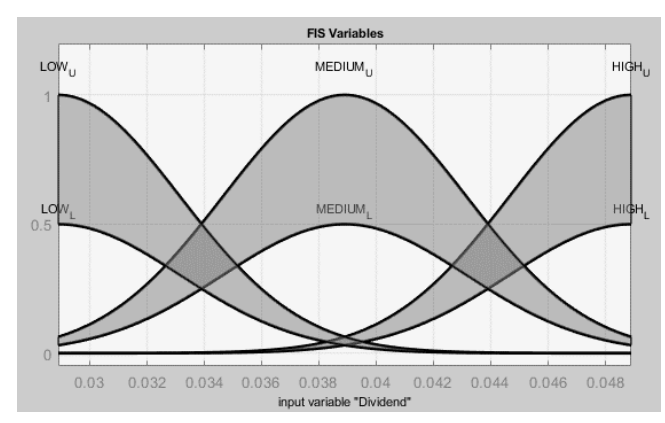

Figure 5. Dividend T2F Membership Function

In the created T2FLS model, 81 IF-THEN rules are created with ANFIS, as shown in Figure 7. Verbal interpretation of fuzzy rules is as follows:

IF risk is low AND return is high AND dividend is high

AND TER is low, THEN ETF is recommended to BUY.

IF risk is low AND return is high AND dividend is high AND TER is medium, THEN ETF is recommended to BUY. ...

IF risk is high AND return is low AND dividend is low AND TER is high, THEN ETF is recommended to SELL.

IF risk is high AND return is low AND dividend is low AND TER is medium, THEN ETF is recommended to SELL.



Figure 6. TER T2F Membership Function

Similarly, additional rules are selected. The rules are set in such a number, which describes the problem.

The created T2FLS model simulates investment decisions in ETF listed stocks on the US stock market. The model can be demonstrated on a case study based on the membership functions and Sugeno rules in the Figure 7. If the ETF shareholding risk is $2.5 \%$, the return is $1.45 \%$, the quarterly dividend is $3 \%$ and the ETF's total expense ratio is $0.34 \%$, according to T2FLS it is appropriate to purchase the ETF in the investment portfolio as the value is exactly equal to 1 .

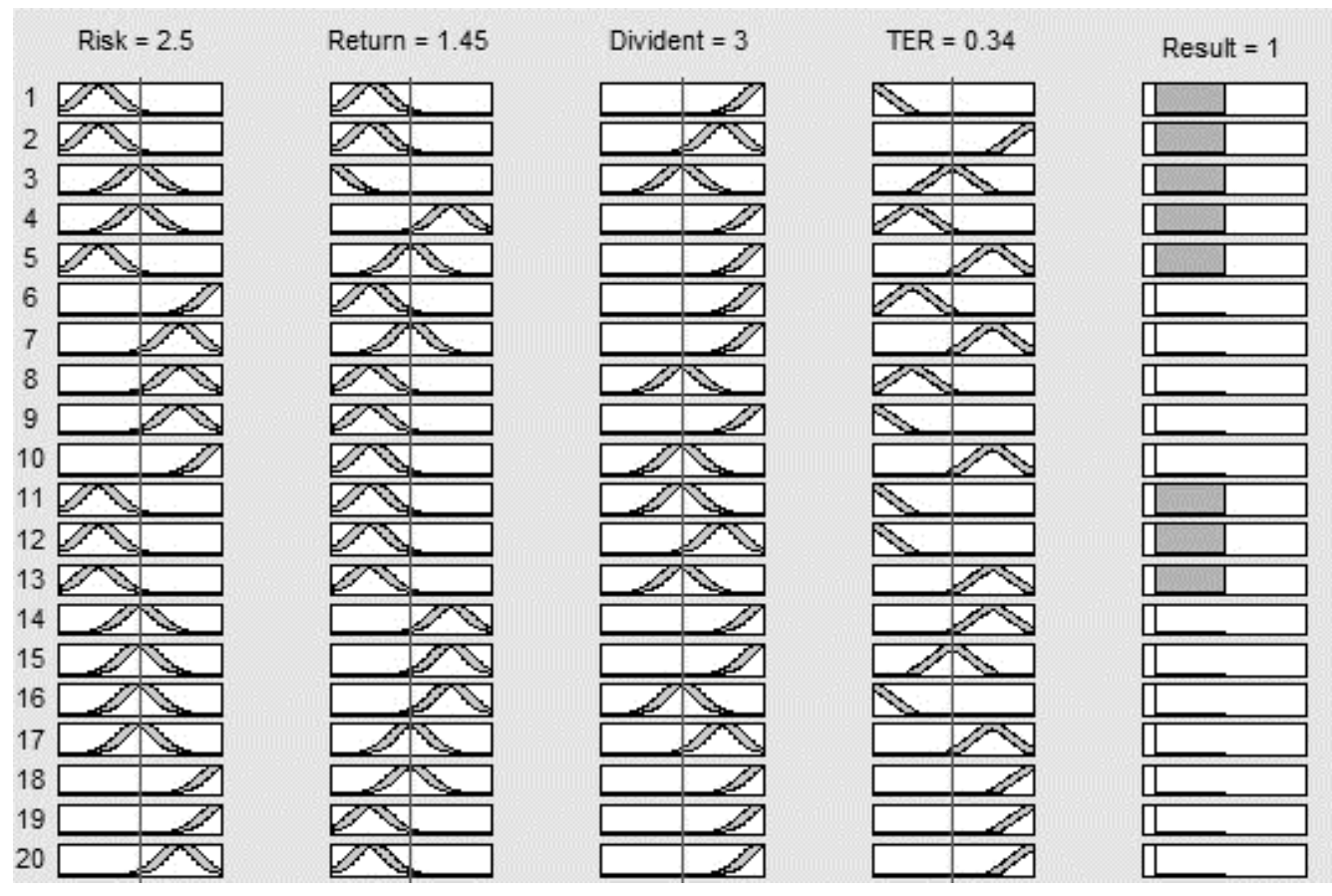

Figure 7. Fuzzy Model Controllerrules

The graphs generated from the created IT2FLS are used to perform the sensitivity analysis. Figure 8 shows the sensitivity analysis for risk and TER. At first glance, it is clear that the higher the risk of investing in the ETF, the more it is recommended not to invest in the fund. Conversely, a very low level of risk is positive for investors with a clear recommendation to buy low risk ETF shares. From the same graph you can read the sensitivity of the total cost of the fund to the overall recommendation whether to invest in the ETF or not. As mentioned above, ETFs are low cost funds with an average cost of $0.4 \%$, with a maximum cost of $0.6 \%$ and a minimum cost of $0.1 \%$. It follows that the TER has no significant influence on the recommendations generated by T2FLS whether to invest or not to invest in the fund, as the TER is very low for all monitored funds. 


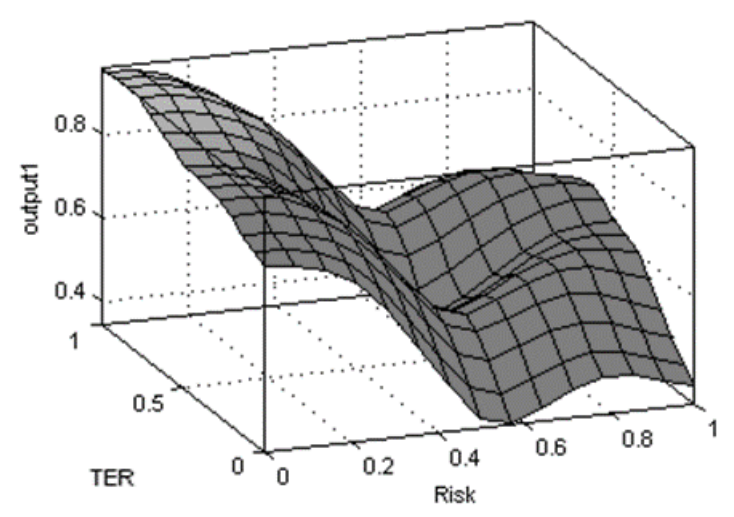

Figure 8. Sensitivity Analysis for Risk and TER

Figure 9 depicts the sensitivity analysis for the return and amount of ETF dividends paid. The graph shows that the higher the return from the ETF, the stronger it is to invest in the fund. Basically, it can be seen if the return is positive, i.e. the investor does not realize the loss from holding ETF shares, so it is recommended to buy the ETF. The sensitivity analysis for the dividend is also shown in the same graph. Selected ETFs are fairly consistent in dividend payout ratio. On average, ETFs pay $3.9 \%$, with a minimum ETF payout of $2.9 \%$ and a maximum dividend of $4.9 \%$. It follows that, like TER, the amount of dividends paid does not have a major impact on investment decisions, as indeed the indicators are almost the same for selected ETFs over the reporting period.

\section{Comparison of Results}

Based on the input and output parameters set, a T2FLS model is created to make ETF investment decisions. Statistical parameters are defined for the assessment and control of the conclusions reached in the T2FLS model. The predictive ability of the created model is determined by comparing the original data and outputs obtained from the model. For this purpose, the root-mean-square error (RMSE) pointer is used, the mathematical notation of which is as follows:



Figure 9. Sensitivity Analysis for Return and Dividend

$$
R M S E=\sqrt{\frac{1}{n} \sum_{t=1}^{n}\left(y_{t}-\dot{y}_{t}\right)^{2}}
$$

The predictive ability of the created model is further evaluated using the determination coefficient (R2) calculated according to the following mathematical formula:

$$
R^{2}=1-\sum_{t=1}^{n} \frac{\left(y_{t}-\dot{y}_{t}\right)^{2}}{\dot{y}_{t}^{2}}
$$

In addition to the above statistical parameters, mean absolute error (MAE) can also be used to evaluate model performance as follows:

$$
M A E=\frac{1}{n} \sum_{t=1}^{n}\left|y_{t}-\dot{y}_{t}\right|
$$

In percentage terms, the mean absolute percentage error (MAPE) can be used to modify the above formula as follows:

$$
M A P E=\frac{1}{n} \sum_{t=1}^{n} \frac{\left|y_{t}-\dot{y}_{t}\right|}{y_{t}} \times 100
$$

wherein $n$ is the number of observations of the data set, $\mathrm{y}_{\mathrm{t}}$ indicates the output predicted by the model for the $\mathrm{t}$-th value, $\dot{y}_{t}$ indicates the original measured output of the data set for the $t$-th value.

Table 2

Statistical Data Analysis of FLS

\begin{tabular}{ccccc}
\hline Model & RMSE & $\mathrm{R}^{\wedge} 2$ & MAE & MAPE \\
\hline T2FLS Sugeno & 0.08286 & 0.93581 & 0.01478 & $15.22 \%$ \\
T1FLS Sugeno & 0.08179 & 0.92568 & 0.01493 & $15.43 \%$ \\
T1FLS Mamdani & 0.12909 & 0.88889 & 0.01667 & $17.26 \%$ \\
\hline
\end{tabular}

The created T2FLS model is compared, based on the above statistical parameters, with the T1FLS model of both Sugeno and Mamdani. Comparison results are presented in Table 2. From the point of view of T1FLS, the Sugeno model with RMSE 0.08179 compared to the Mamdani 0.12909 model. Better results achieved T2FLS Sugeno with 0.08286 . Also, the determination coefficient provides very promising results in terms of Sugeno's ability. It can be stated that T2FLS is suitable for investment analysis because it can better deal with the uncertainty and chaos that prevails in the financial market and provides constant results. An indisputable advantage for T2FLS in the financial markets is the ability to accommodate a higher degree of uncertainty than T1FLS. T2FLS has demonstrated computational flexibility and suitability for modeling complex, dynamic and nonlinear relationships that are common in financial markets. 


\section{Discussion}

It is well known that the stock market is a very complex system that exhibits dynamic and highly nonlinear behavior. For this reason, it is not easy to predict or at least determine the direction of its future development. The aim of the presented paper was to create a suitable and simple model that will serve as a support for deciding on profitable opportunities in the stock market and thus reduce investor uncertainty. The model applied an interval type-2 fuzzy model, which is able to contain a higher degree of uncertainty resulting from the nature of the examined markets. The developed model is very limited; however, it illustrates the possibility of further use of T2FLS, which is applied to a dominant extent in technical industries. The presented model could be further extended by other important input variables and create a more complex revised model, however, the aim of this paper was to keep the set of input variables and the model as simple as possible so that it can be used by an inexperienced investor. As Doskočil \& Dostál (2017) further state, only a proven model can be used as a tool for investment decisions. For this reason, the proposed neuro-fuzzy model cannot be considered final and only correct. It is also necessary to discuss some limits and limitations of fuzzy logic. Fullér (1995) states that it is not guaranteed that any fuzzy model created will remain stable and robust. A major limitation is the fact that fuzzy logic has no memory and, moreover, is not able to learn from the presented data. In addition, determining the shape and size of the membership function is a very complex and subjective matter that can ultimately affect the performance of the entire model. Verification of the fuzzy model also requires loop testing, which can cause difficulties.

\section{Conclusion}

The decision-making process on investment opportunities is a widely discussed topic today. Artificial intelligence models used in many fields can be used for this purpose. This paper introduces the implementation of type2 fuzzy logic to the investment decision problem. The application of T2FLS is still inadequate especially in the area of financial markets, although there is a high degree of uncertainty, chaos and non-linearity especially in financial markets. In other words, equity markets in particular provide sufficient scope for examining the performance of a higher degree of fuzzy logic.

The paper is an easy-to-use model that contains simple input variables that fundamentally influence the decision to invest in exchange-traded funds in the US stock market. Specifically, the accuracy of the T2FLS Sugeno model is almost $93.6 \%$ compared to the T1FLS Sugeno 92.6\%, respectively T1FLS Mamdani $88.9 \%$ measured by determination coefficient. Similarly, error rates such as RMSE, MAE and MAPE sound in favor of T2FLS on the equity markets. The higher performance of T2FLS for investment decisions is mainly due to the use of the membership function of the general type-2 fuzzy set which is three-dimensional and includes the footprint of uncertainty (FOU). It is a new third dimension of the fuzzy set that provides additional degrees of freedom and allows you to directly model and process numerical and linguistic uncertainties

Using T2FLS can lead to more realistic and accurate results than T1FLS. For further research, it would be appropriate to extend the proposed model to include other significant underlying indicators or to include technical and psychological indicators and to monitor the strength of the revised model in other stock markets

\section{Acknowledgements}

This paper was supported by project No. FP-J-20-6246 'The Use of Artificial Intelligence in Business IV' and No. FP-S-206376 'Modeling and optimization of business processes in conditions of digital transformation' from the Internal Grant Agency at Brno University of Technology

\section{Reference}

Alhassan, M. S. E., \& Hagras, H. (2018). Towards Congestion Control Approach Based on Weighted Random Early Detection and Type-2 Fuzzy Logic System. 10th Computer Science and Electronic Engineering (CEEC). IEEE, 2018, 71-74.

Arenas, M., Bilbao, \& Rodriguez, M. V. (2001). A fuzzy goal programming approach to portfolio selection. European Journal of Operational Research, 133, 287-297. https://doi.org/10.1016/S0377-2217(00)00298-8

Bernardo, D., Hagras, H., \& Tsang, E. (2012). An interval type-2 Fuzzy Logic based system for model generation and summarization of arbitrage opportunities in stock markets. 12th UK Workshop on Computational Intelligence (UKCI). IEEE, 1-7. https://doi.org/10.1109/UKCI.2012.6335765

Broz, Z., \& Dostal, P. (2013). Fuzzy Logic Decision Support for Long-Term Investing in the Financial Markets. Nostradamus: Modern Methods of Prediction, Modeling and Analysis of Nonlinear Systems. Berlin, Heidelberg: Springer. https://doi.org/10.1007/978-3-642-33227-2_14

Camara, R. C., Cuzzocrea, A., Grasso, G. M., Leung, C. K., Powell, S. B., Souza, J., \& Tang, B. (2018). Fuzzy LogicBased Data Analytics on Predicting the Effect of Hurricanes on the Stock Market. In: 2018 IEEE International Conference on Fuzzy Systems (FUZZ-IEEE). IEEE, 2018. 1-8. https://doi.org/10.1109/FUZZ-IEEE.2018.8491523

Castillo, O., Melin, P., \& Castro, R. J. (2013). Computational intelligence software for interval type-2 fuzzy logic. Computer Applications in Engineering Education, 21(4), 737-747. https://doi.org/10.1002/cae.20522 
Castillo, O., Melin, P., Kacprzyk, J., \& Pedrycz, W. (2007). Type-2 Fuzzy Logic: Theory and Applications. IEEE International Conference on Granular Computing (GRC). IEEE, 145-145. https://doi.org/10.1109/GrC.2007.118

Chang P. C., Fan C. Y., \& Lin, J. L. (2011). Trend discovery in financial time series data using a case based fuzzy decision tree. Expert Systems with Applications, 38, 6070-6080. https://doi.org/10.1016/j.eswa.2010.11.006

Chen, H. M, Hu, C. F., \& Yeh, W. C. (2019). Option pricing and the Greeks under Gaussian fuzzy environments. Soft Computing. 1-24. https://doi.org/10.1007/s00500-019-03876-w

Chen, Y., Wang, D., \& Ning, W. (2018). Forecasting by TSK general type-2 fuzzy logic systems optimized with genetic algorithms. Optimal Control Applications and Methods, 39(1), 393-409. https://doi.org/10.1002/oca.2353

Doskocil, R., \& Dostal, P. (2017). Project success evaluation model based on FIS. In Perspectives of business and entrepreneurship development in digital age: economics, management, finance and system engineering from the academic and, practitioners' views, 149-155.

Dostal, P., \& Lin, C. (2018). Business Applications of Fuzzy Logic. The Oxford Handbook of Computational Economics and Finance (pp. 360-396).USA: Oxford University Press. https://doi.org/10.1093/oxfordhb/97801998 44371.013.14

Dostal, P. (2011). Advanced Decision Making in Business and Public Services. Brno: Academic Publishing House CERM.

Dourra, H., \& Pepe, S. I. Y. (2002). Investment using technical analysis and fuzzy logic. Fuzzy Sets and Systems, 127, 221-240. https://doi.org/10.1016/S0165-0114(01)00169-5

Esfahanipour, A., \& Aghamiri, W. (2010). Adapted Neuro-Fuzzy Inference System on indirect approach TSK fuzzy rule base for stock market analysis. Expert Systems with Applications, 37(7), 4742-4748. https://doi.org/10.10 16/j.eswa.2009.11.020

Fang, Y., Lai, K. K., \& Wang, S. (2006). Portfolio rebalancing model with transaction costs based on fuzzy decision theory. European Journal of Operational Research, 175(2), 879-893. https://doi.org/10.1016/j.ejor.2005.05.020

Escobar, A., Moreno, J., \& Munera, S. (2013). A Technical Analysis Indicator Based On Fuzzy Logic. Electronic Notes in Theoretical Computer Science, 292, 27-37. https://doi.org/10.1016/j.entcs.2013.02.003

Fuller, R. (1995). Neural Fuzzy Systems. Åbo Akademis tryckeri, Åbo, ESF Series A.

Gupta, P., Mehlawat, M. K., \& Saxena, A. (2008). Asset portfolio optimization using fuzzy mathematical programming. Information Sciences, 178(6), 1734-1755. https://doi.org/10.1016/j.ins.2007.10.025

Gautam, S. S., \& Abhishekh. (2019). A Novel Moving Average Forecasting Approach Using Fuzzy Time Series Data Set. Journal of Control, Automation and Electrical Systems. 1-13. https://doi.org/10.1007/s40313-019-00467-w

Hasuike, T., \& Ishii, H. (2009). A portfolio selection problem with type-2 fuzzy return based on possibility measure and interval programming. IEEE International Conference on Fuzzy Systems. IEEE, 267-272. https://doi.org/10.11 09/FUZZY.2009.5277134

Huarng, K. H., \& Yu, T. H. K. (2005). A type 2 fuzzy time series model for stock indexforecasting. Phys. A, Stat. Mech. Appl., 353, 445-462. https://doi.org/10.1016/j.physa.2004.11.070

Jana, D. K., \& Ghosh, R. (2018). Novel interval type-2 fuzzy logic controller for improving risk assessment model of cyber security. Journal of Information Security and Applications. 40, 173-182. https://doi.org/10.1016/j.ji sa.2018.04.002

Jankova, Z., \& Dostal, P. (2019). Expertní systém type-2 fuzzy logika pro investicní analýzu. Scientific Papers of the University of Pardubice, Series D, 47(27), 79-90.

Jankova, Z. (2019). Application of Artificial Neural Networks and Fuzzy Logic in Stock Trading. In Proceedings of the 33rd International Business Information Management Association Conference (IBIMA). Granada, Spain: IBIMA, 2610-2619.

Jiang, J. A., Syue, C. H., Wang C. H, Wang, J. C., \& Shieh, J. S. (2018). An Interval Type-2 Fuzzy Logic System for Stock Index Forecasting Based on Fuzzy Time Series and a Fuzzy Logical Relationship Map. IEEE Access. 6, 6910769119. https://doi.org/10.1109/ACCESS.2018.2879962

Jilani, T., \& Burney, S. (2008). A refined fuzzy time series model for stock market forecasting. Physica A, 387, 28572862. https://doi.org/10.1016/j.physa.2008.01.099

Karnik, N. N., \&Mendel, J. M. (2001). Centroid of a type-2 fuzzy set. Information Sciences, 132, $195-220$. https://doi.org/10.1016/S0020-0255(01)00069-X

Kayacan, E., Sarabakha, A., Coupland, S., John, R., \& Khanesar, M. A. (2018). Type-2 fuzzy elliptic membership functions for modeling uncertainty. Engineering Applications of Artificial Intelligence, 70, $170-183$. https://doi.org/10.1016/j.engappai.2018.02.004

Liang, Q., \& Mendel, J. M. (2000). Interval type-2 fuzzy logic systems: theory and design. IEEE Transactions on Fuzzy Systems, 8(5), 535-550. https://doi.org/10.1109/91.873577 
Liu, P., Gao, H., \& Ma, J. (2019). Novel green supplier selection method by combining quality function deployment with partitioned Bonferroni mean operator in interval type-2 fuzzy environment. Information Sciences, 490, $292-316$. https://doi.org/10.1016/j.ins.2019.03.079

Liu, Z., \& Zhang, T. (2019). A second-order fuzzy time series model for stock price analysis. Journal of Applied Statistics, 1-13.https://doi.org/10.1080/02664763.2019.1601163

Liu, C. F., Yeh, C. Y., \& Lee, S. J. (2012). Application of type-2 neuro-fuzzymodeling in stock price prediction, Appl. Soft Computing, 12(4), 1348-1358. https://doi.org/10.1016/j.asoc.2011.11.028

Mayilvaganan, M. K., \& Naidu, K. B. (2011). Comparison of membership functions in adaptive-network-based fuzzy inference system (ANFIS) for the prediction of groundwater level of a watershed. Journal of Computer Applications Research and Development, 1(1), 35-42.

Medasani, S., Kim, J., \& Krishnapuram, R. (1998). An overview of membership function generation techniques for pattern recognition. International Journal of Approximate Reasoning, 19(3/4), 391-417. https://doi.org/10.1016/S0888613X(98)10017-8

Melin, P., \& Castillo, O. (2014). A review on type-2 fuzzy logic applications in clustering, classification and pattern recognition. Applied Soft Computing, 21, 568-577. https://doi.org/10.1016/j.asoc.2014.04.017

Mendel, J. M. (2007). Advances in type-2 fuzzy sets and systems. Information Sciences, 177(1), 84-110. https://doi.org/10.1016/j.ins.2006.05.003

Mendel, J. M. (2001). Uncertain Rule-Based Fuzzy Logic Systems: Introduction and New Directions, Prentice-Hall, Upper-Saddle River.

Naranjo, R., Arroyo, J., \& Santos, M. (2018). Fuzzy modeling of stock trading with fuzzy candlesticks. Expert Systems with Applications, 93, 15-27. https://doi.org/10.1016/j.eswa.2017.10.002

Othman, S., \& Schneider, E. (2010). Decision making using fuzzy logic for stock trading. International Symposium on Information Technology. IEEE, 880-884. https://doi.org/10.1109/ITSIM.2010.5561564

Pulido, M., \& Melin, P. (2016). Genetic algorithm and Particle Swarm Optimization of ensemble neural networks with type-1 and type-2 fuzzy integration for prediction of the Taiwan Stock Exchange. In: 2016 IEEE 8th International Conference on Intelligent Systems (IS). IEEE, 2016, 140-145. https://doi.org/10.1109/IS.2016.7737413

Rajab, S., \& Sharma, V. (2019). An interpretable neuro-fuzzy approach to stock price forecasting. Soft Computing, 23(3), 921-936.

Rao, V. N., Reddy, K. N., \& Sangam, S. (2017). Application of Fuzzy Logic in Financial Market for Decision Making. International Journal of Advanced Research in Computer Science, 8(3), 382-386.

Runkler, T., Coupland, S., \& John, R. (2017). Interval type-2 fuzzy decision making. International Journal of Approximate Reasoning, 80, 217-224. https://doi.org/10.1016/j.ijar.2016.09.007

Rustam, Z., Vibranti, D. F., \&Widya, D. (2018). Predicting the direction of Indonesian stock price movement using support vector machines and fuzzy Kernel C-Means. AIP Conference Proceedings, 020208-1-020208-7. https://doi.org/10.1063/1.5064205

Talpur, N, Salleh, M. N. M., \& Hussain, K. (2017). An investigation of membership functions on performance of ANFIS for solving classification problems. IOP Conference Series: Materials Science and Engineering, 226. https://doi.org/10.1088/1757-899X/226/1/012103

Tang, G., Chiclana, F., Lin, X. C., \& Liu, P (2020). Interval type-2 fuzzy multi-attribute decision-making approaches for evaluating the service quality of Chinese commercial banks. Knowledge-Based Systems, 193, 10543. https://doi.org/10.1016/j.knosys.2019.105438

Taskin, A., \& Kumbasar, T. (2015). An Open Source Matlab/Simulink Toolbox for Interval Type-2 Fuzzy Logic Systems. IEEE Symposium Series on Computational Intelligence. IEEE, 1561-1568. https://doi.org/10.1109/SSCI.2015.220

Tung, K. T., \& Le, M. H. (2017). An Application of Artificial Neural Networks and Fuzzy Logic on the Stock Price Prediction Problem. JOIV: International Journal on Informatics Visualization, 1(2), 40-49. https://doi.org/10.3 0630/joiv.1.2.20

Vella, V., \& Lon Ng, W. (2016). Improving risk-adjusted performance in high frequency trading using interval type-2 fuzzy logic. Expert Systems with Applications, 55, 70-86. https://doi.org/10.1016/j.eswa.2016.01.056

Wang, W. (2018). A big data framework for stock price forecasting using fuzzy time series. Multimedia Tools and Applications, 77(8), 10123-10134. https://doi.org/10.1007/s11042-017-5144-5

Wang, H., Ju, Y., Liu, P., Ju, D., \& Liu, Z. (2018). Some trapezoidal interval type-2 fuzzy Heronian mean operators and their application in multiple attribute group decision making. Journal of Intelligent \& Fuzzy Systems, 35(2), 23232337. https://doi.org/10.3233/JIFS-17636 
Wang, H., Liu, P., \& Liu, Z. (2018). Trapezoidal interval type-2 fuzzy maclaurin symmetric mean operators and their applications to multiple attribute group decision making. International Journal for Uncertainty Quantification, 8(4), 343-360. https://doi.org/10.1615/Int.J.UncertaintyQuantification.2018020768

Wang J., \& Wang, J. (2015). Forecasting stock market indexes using principle component analysis and stochastic time effective neural networks. Neurocomputing, 156, 68-78. https://doi.org/10.1016/j.neucom.2014.12.084

Yu, P., \& Yan, X. (2019). Stock price prediction based on deep neural networks. Neural Computing and Applications, 1-20.

Zadeh, L. A. (1965). Fuzzy sets. Information and Control, 8(3), 338-353. https://doi.org/10.1016/S0019-9958(65)90241-X

Zarandi, M. H., Rezaee, B., Turksen, I. B., \& Neshat, E. (2009). A type-2 fuzzy rule-based expert system model for stock price analysis. Expert Systems with Applications 36(1), 139-154. https://doi.org/10.1016/j.eswa.2007.09.034

Zhang, W., Zhang, S., Zhang, S., Yu, D., \& Huang, N. (2017). A multi-factor and high-order stock forecast model based on Type-2 FTS using cuckoo search and self-adaptive harmony search. Neurocomputing, 240, 13-24. https://doi.org/10.1016/j.neucom.2017.02.054

\section{Authors' Biographies}

Zuzana Janková is a Ph.D. student at Brno University of Technology (BUT), Faculty of Business and Management, Institute of Informatics. She deals with finance and investment management. Above all, she focuses on the creation of models for decision support and prediction in financial markets through artificial intelligence tools, especially fuzzy logic, artificial neural networks and hybrid neuro-fuzzy models. She has lectured at the National Chengchi University, Taiwan and at the University of Economics in Bratislava, Slovakia.

Dipak Kumar Jana did Ph.D. from Indian Institute of Engineering Science and Technology, Shibpur and did his postgraduation (M.Sc) in Applied Mathematics with specialization in Operations Research from Vidyasagar University, West Bengal. He has qualified in National Eligibility Test (NET-CSIR) for Junior Research Fellow (JRF) and GATE. He is working as Professor \& HOD in School of Applied Science \& Humanities, Haldia Institute of Technology. Dr. Jana is a member of Operational Research Society of India, Indian Science Congress Association, Calcutta Mathematical Society. Dr. Jana has published more than 86 papers in esteemed International Journals and 6 books. At 17th China Uncertain System annual meeting Jana won the Outstanding Thesis Award of Uncertain Theory, China Operational Research Association, Uncertain System Branch, 19 July, 2019.

Petr Dostál is a Professor of economics and management at Brno University of Technology (BUT), Faculty of Business and Management, Institute of Informatics. Field of interest is the use of soft computing and artificial intelligence such as fuzzy logic, artificial neural networks, evolutionary algorithms, and the theory of chaos in business and public services. As an economic and organization adviser, he has worked in private firms and institutions. He is a member of international institutions, program and organizing committees, scientific and editorial advisory boards.

The article has been reviewed.

Received in December 2019; accepted in April 2021.

This article is an Open Access article distributed under the terms and conditions of the Creative Commons Attribution 4.0 (CC BY 4.0) License (http://creativecommons.org/licenses/by/4.0/). 